\title{
Novas achegas ao debate gramatical na Academia Galega na década de 60 da anterior centuria
}

\author{
Xosé Ramón Freixeiro Mato \\ Universidade da Coruña \\ freixei@udc.gal
}

Recibido o 26/07/2017

Aceptado o 01/11/2017

\section{New insights into the grammatical debates of the} Real Academia Galega, 1960-1970

\begin{abstract}
Resumo
Após unhas consideracións previas sobre a noción tradicional de gramática e o valor simbólico da gramática normativa, no presente traballo relátase a historia interna do fracasado proxecto de a Academia Galega elaborar unha gramática oficial da entidade nos inicios do mandato de Sebastián Martínez-Risco como presidente na década de 60 do século pasado á luz da nova documentación coñecida, tanto édita como inédita; préstase especial atención ás dificultades con que se encontrou a Comisión de gramática encargada de levar a cabo o traballo e ao informe presentado por Ramón Piñeiro, que supuxo a paralización do proxecto. A seguir, faise tamén o relato interno dos procesos de elaboración das dúas gramáticas galegas publicadas nesa década, a de Ricardo Carvalho Calero e a de Leandro Carré Alvarellos, a primeira con toda a axuda solidaria do grupo de Galaxia que dominaba a Academia e a segunda co labor solitario dun autor que non contaba con apoios relevantes para as súas propostas lingüísticas na entidade. Por último, dáse conta dunha síntese gramatical que en finais da década fora encargada pola Xunta de Goberno da Academia e que ficou inédita, determínase a súa autoría e datación, descríbese o seu contido e finalmente realízase unha análise valorativa dela.
\end{abstract}

\section{Palabras chave}

Historiografía gramatical; gramática galega; Real Academia Galega; Editorial Galaxia

\section{Sumario}

1. Introdución. 2. A preocupación pola gramática da Academia na presidencia de Martínez-Risco. 2.1. A gramática como grande obxectivo do seu mandato. 2.2. A Comisión de gramática da RAG e as súas dificultades. 2.3. O informe de Piñeiro e a paralización do proxecto gramatical. 3. A produción gramatical na década de 60 . 3.1. O traballo solidario de Carvalho Calero. 3.2. O labor solitario de Carré Alvarellos. 4. Unha gramática inédita de finais da década: Epítome de gramática galega. 4.1. Autoría e datación. 4.2. Descrición e valorización. 5. Conclusión.
Abstract

The article begins with a critical introductory review of traditional ideas about grammar and the symbolic importance of a grammatical standard, before focusing on the abortive attempt by the Real Academia Galega (RAG) in the 1960s to create an official grammar of the Galician language. Using a range of contemporary sources, many of them unpublished until now, the paper offers new insight into the process instigated by Sebastián Martínez-Risco during the early years of his presidency of the RAG, including the challenges and difficulties faced by the grammar committee and the report by Ramón Piñeiro that led to the project's suspension. The article also explores the successful completion of two other grammar projects during the same period, by Ricardo Carvalho Calero and Leandro Carré Alvarellos, respectively: the first, with the institutional endorsement and support of the influential Galaxia publishing group; the second, as a solitary endeavour by the author, without any official backing or recognition. The paper concludes with a review of the date, authorship and contents of the never-published Short Grammar of the Galician Language, commissioned by the RAG at the end of the 1960s, offering a critical appraisal of the quality and importance of the work as a whole.

Keywords Historiography of grammar; Galician grammar; Real Academia Galega (Royal Galician Academy); Editorial Galaxia

Contents

1. Introduction. 2. Grammar debates in the RAG during the presidency of Sebastián Martínez-Risco. 2.1. Martínez-Risco's personal commitment to the creation of a Galician grammar. 2.2. Challenges faced by the RAG grammar committee. 2.3. The Piñeiro report and the suspension of the project. 3. Grammar writing in the 1960s. 3.1. Carvalho Calero: one for all and all for one. 3.2. The solitary mission of Carré Alvarellos. 4. The unpublished grammar: A Short Grammar of the Galician Language. 4.1. Date and authorship. 4.2. Description and evaluation. 5. Conclusion. 


\section{INTRODUCIÓN}

O proxecto, fracasado, de a Real Academia Galega (RAG) elaborar unha gramática do galego na década de 60 do século XX, baixo a presidencia de Sebastián Martínez-Risco, foi abordado nalgún traballo anterior (Freixeiro 1994: 166-179). Mais, transcorridos xa bastantes anos, semeIla conveniente retomar este tema á luz de nova información existente ao respecto, entre ela a correspondencia publicada nas últimas décadas con personalidades da cultura galega directamente involucradas nese proceso, como Ramón Piñeiro, Carvalho Calero', Fernández del Riego etc., alén da que permanece aínda inédita tanto no arquivo particular de Martínez-Risco (no sucesivo AMR) como no arquivo da Academia Galega (no sucesivo ARAG), que custodian igualmente outra documentación de interese para o tema. Entre toda esa documentación incorpórase a relativa a Leandro Carré Alvarellos, que apenas fora tomado en consideración anteriormente. $\mathrm{Na}$ análise do proceso gramatical desa década insírese tamén a historia relativa á elaboración das dúas gramáticas que se publicaron no período, a do propio Carré e a de CarvaIho, pois ambas están directamente ligadas ao proxecto gramatical da RAG, como tamén o está o inédito Epítome de gramática galega de que se dará noticia. Mais antes de iniciar o relato interno das peripecias seguidas por esas propostas gramaticais, convén, a modo de introdución, facer algunhas breves consideracións a respecto do que representa a gramática prescritiva ou normativa, pois desta natureza eran tanto o proxecto fracasado como os levados a cabo na década, e do seu valor simbólico para a comunidade lingüística.

Cómpre indicar, de entrada, que a lingua galega iniciou serodiamente a súa 'gramatización', ou grammatisation na expresión literal de Auroux, quen sinala o Renacemento europeo como o punto de inflexión dun proceso de produción de dicionarios e gramáticas (Auroux 1994: 9) que no caso galego só chegou a se substanciar na segunda metade do século XIX. Tal proceso tivo lugar a partir da tradición grecolatina en exclusiva e constitúe para este autor, após a invención da escritura, a segunda revolución tecnolingüística, cuxas consecuencias prácticas para a organización das sociedades humanas "sont considérables" (Auroux 1994: 71). Non torna estraño, pois, que as primeiras persoas e entidades que dalgún modo tentaron unha planificación da lingua galega con vistas á súa revitalización social fixasen a cuestión gramatical como un obxectivo a alcanzar.

Gramática significa literalmente en grego 'ensino das letras', cuxa tradución latina é 'litteratura'. Como a primeira das 'artes liberais', a gramática clásica constaba de dúas partes, a recte loquendi scientia e a poetarum enarratio, bipartición fundada no papel do escritor como mestre do idioma e na necesidade dunha explicación da linguaxe dos poetas naquilo que se afasta do uso vivo da lingua. Estas dúas partes fóronse desenvolvendo independentemente e chegaron ao ensino moderno do idioma nas escolas como 'teoría gramatical' ou gramática en sentido estrito e 'lectura', a subsistiren igualmente no estudo e pesquisa actuais da filoloxía como'lingüística' e 'ciencia da literatura', respectivamente (Lausberg 1990: 72-73). Canto á recte loquendi scientia, o alumnado debía ser instruído no uso oral e escrito correctos do idioma, facendo parte as categorías de 'correcto' (recte) e'incorrecto' (vitiose) da teoría das virtutes, de modo que a gramática se pon en relación coa ética. A poetarum enarratio xorde da necesidade de seleccionar a materia da lectura con criterios gramaticais, expresivos, literarios e éticos, sendo fundamental que esa selección ofreza exemplos para a imitación estilística, literaria e activa (ética); os bos autores fornecen nas súas obras exemplos que serven como modelos para a imitación tanto no relativo á corrección gramatical como ao estilo e ao exercicio de composición literaria, de modo que a obra deles así seleccionada se converte na única materia que se debe recomendar como lectura (Lausberg 1990: 76).

Pódese dicir que esta é a concepción clásica e máis tradicional de gramática, que en boa parte está presente no proxecto de dicionario da RAG desde a súa fundación e inclusive nas súas primeiras normas ortográficas e morfolóxicas de inicios da década de 70 (Real Academia Gallega 1971), alén de na gramática de Galaxia dos anos 60, pois todos toman como modelo ou finali-

${ }^{1}$ Coa intención de respectar a derradeira vontade do autor, que nos anos finais da súa vida asinaba os seus textos como "Carvalho Calero", manterase esa grafía para o seu primeiro apelido nas referencias persoais; cando se citaren os seus traballos utilizarase, como é lóxico, a grafía orixinal con que foron publicados. 
dade a lingua literaria (Alonso Pintos 2002: 107-117). Porén, existen outras conceptualizacións da gramática do punto de vista social e político; na opinión de Agustini (2004: 16) a gramática é parte da constitución dun saber lingüístico que fai historia e que afecta as formas da sociedade, de modo que non só é un manual de aplicación de regras lingüísticas, mais igualmente lugar de interpretación do proceso de constitución da identidade nacional e da produción de sentidos das institucións sociais. No caso concreto do Brasil, considera esta autora que a construción dunha gramática como instrumento tecnolóxico de gramatización do portugués-brasileiro fai parte do modo como a sociedade brasileira se constitúe historicamente. Ao trasladarmos estas consideracións ao caso galego, achamos que a serodia e escasa tradición gramatical (Sánchez Rei 2005) comeza a se desenvolver na segunda metade do século XIX, xusto cando, so as denominacións de 'provincialismo' primeiro e 'rexionalismo' despois, emerxe lentamente o proceso de construción da identidade política galega. E, dalgún modo, non deixa de ser certo que cada paso que se foi dando no afianzamento da tradición gramatical do galego supuxo máis un chanzo nesa construción identitaria. Por iso torna significativo o interese que tivo o emerxente nacionalismo galego das Irmandades da Fala por elaborar gramáticas, como tamén o tivo a RAG desde os inicios e nomeadamente na década de 60 de que se vai tratar nestas páxinas.

Por súa vez, Bagno (2001: 15) critica a gramática normativa e, por extensión, a ideoloxía gramatical. Para el a gramática tradicional é a ideoloxía que dá alento e vigor a un "gênero literário conhecido como gramática normativa"2, unha "coisa material" que podemos adquirir, apalpar e someter aos nosos sentidos. Na realidade, trataríase dunha inversión da realidade histórica, pois as gramáticas xurdiron precisamente para describiren e fixaren como regras e padróns as manifestacións lingüísticas utilizadas espontaneamente polos escritores considerados dignos de admiración e imitación nunha época determinada. Neste sentido, a gramática normativa é consecuencia do uso da lingua, ao cal está subordinada e do que depende; no entanto, converteuse nun mecanismo ideolóxico de poder e de control "de uma classe social dominante sobre as demais" (Bagno 2001: 39). Arremete este autor contra a gramática como causante do preconcepto lingüístico no Brasil e como elemento de exclusión social. O que na realidade pretende é romper a "falsa sinonímia" entre ensino da lingua e ensino da gramática, entendida esta como "mera prescrição de normas arcaicas" e "conceito empobrecido e empobrecedor" (Bagno 2001: 306). A se apoiar en Bourdieu, considera esta concepción tradicional da gramática como unha institución "que estabelece e santifica a distinção entre o certo e o errado, entre o que 'se deve' e o que 'se não deve dizer', explorando as diferenças objetivas entre as variedades lingüísticas, tal como a instituição religiosa define o sagrado e o profano". En canto a lingüística insiste en mostrar a lingua como un contínuum de variedades, a gramática enfatiza o descontinuo e estabelece radicais diferenzas dicotómicas entre a'lingua lexítima' ou 'exemplar' e os patois, de modo que instituír, consagrar ou abenzoar unha norma lingüística padrón se converte, segundo o autor, en sinónimo de destituír, execrar, excomungar ou anatematizar as variedades (Bagno 2001: 312-313). Se no Brasil as variedades populares da lingua foron estigmatizadas, o caso do galego é bastante diferente, pois é a propia lingua no seu conxunto, e con ela as persoas que a falan, a que sufriu discriminación e foi obxecto de exclusión; con todo, algunha conexión existe cando as elites galeguistas representadas pola RAG e por Galaxia pugnaban na posguerra franquista por unha gramática de base literaria na perspectiva dunha norma culta afastada da fala popular; o contrapunto a este posicionamento púxoo o método de galego elaborado nos inicios da década de 70 polo Departamento de Filoloxía Románica da USC, baseado na fala popular e dialectal (Alonso Pintos 2002: 117-120).

Continuando coa visión doutra autora brasileira, Agustini (2004), a gramática —entendida como a gramática tradicional — traballa na institución da unidade imaxinaria dunha lingua, dunha nación ou dun estado, de maneira que a lingua nacional non se define institucionalmente en relación coas persoas que a falan, mais en relación cos obxectos simbólicos sociohistóricos que a representan, a gramática un deles. É, por tanto, esta un obxecto simbólico que se referencia na escrita, o que permite estabelecer unha relación entre gramática e literatura: "a literatura aparece na gramática como prática linguageira legítima e correta de que se vale o gramático para

\footnotetext{
${ }^{2}$ Neste caso e en todos os sucesivos os subliñados con tipografía diferente son da responsabilidade do autor concreto de cada texto reproducido, incluída a correspondencia que se citará nos diferentes capítulos do traballo.
} 
instituir/legitimar as regras gramaticais via os exemplos" (Agustini 2004: 11). Ao mesmo tempo, a relación entre gramática e literatura funciona segundo ela nunha dupla dirección: a segunda produce unha realidade lingüística para a primeira, que por súa vez produce para os autores que aparecen nela a imaxe modélica que institúe ou lexitima unha regra. Así, a gramática adquire importancia na consagración dun autor ou dunha autora, xa que a converte en modelo de comportamento lingüístico correcto; e, por súa vez, esa consagración da autoría "dá credibilidade à gramática, o que produz uma circularidade" (Agustini 2004: 12).

En conclusión, a gramática tradicionalmente estivo asociada á literatura, e tal asociación produciuse igualmente nos ámbitos galeguistas que aspiraban a unha gramática galega de carácter oficial; mais tamén a gramática adquiriu un valor identitario, como máis un elemento simbólico constitutivo e demostrativo dunha realidade política e/ou cultural propia, e así o entendeu o galeguismo, cando menos dun modo difuso; do mesmo xeito, unha gramática normativa baseada na fala culta das persoas ilustradas fixo parte igualmente das aspiracións galeguistas, aínda tendo en conta que a verdadeira lingua de cultura no territorio galego foi o castelán durante séculos. Se noutras realidades lingüísticas, sobre todo socialmente moi desiguais e desequilibradas, a defensa da gramática normativa pode xulgarse excesiva, excluínte e ameazante para a enriquecedora variedade do idioma, no caso do galego a elaboración dunha gramática normativa con recoñecemento oficial foi vista polo movemento galeguista como ferramenta imprescindíbel para a propia supervivencia do galego e tamén como instrumento necesario para a súa dignificación social e para a construción dun modelo de lingua culta unificado e con prestixio. Ese foi o motivo que guiou as actuacións da RAG na década de 60 da anterior centuria para conseguir a elaboración dunha gramática oficial da entidade, que non chegou a se materializar polas causas que a seguir se tentarán explicitar; e foi tamén o obxectivo presente nas dúas gramáticas editadas no período e mesmo dese epítome gramatical que ficou inédito.

\section{A preocupación pola gramática da Academia na presidencia de Martínez-Risco}

Sebastián Martínez-Risco presidiu a RAG desde 1960 até a súa morte en 1977. O recoñecemento que posuía como xurista, escritor e orador convertérano en firme candidato para substituír o desaparecido presidente Manuel Casás Fernández; e, con efecto, foi elixido para ese cargo o 9-10-60. Coa súa presidencia a RAG entra nunha nova etapa caracterizada por unha maior proxección pública e un intenso dinamismo interior, que se manifesta na continuada renovación dos seus membros para ir dando entrada a personalidades do ámbito galeguista, nomeadamente vinculadas ao grupo de Galaxia, a que o propio Sebastián pertencía, e da oposición ao réxime franquista. $\mathrm{O}$ acceso a este cargo vaino converter no símbolo representativo da cultura galega, tanto no interior do país como na emigración peninsular, europea e, nomeadamente, americana. No desempeño do cargo foi un presidente conciliador e dialogante, que soubo exercer o seu posto mantendo un difícil equilibrio entre as persoas nuns momentos complicados, non faltos de tensións e intereses persoais ou de grupo contrapostos. Arbitrou e mediou para resolver problemas, a procurar sempre unha relación amigábel con todas as persoas, polo que obtivo o respecto e a simpatía xeral. Conseguiu tamén grandes metas para a entidade que presidía e para a cultura galega en xeral, mais algún dos obxectivos propostos nunca chegou a se materializar. Este é o caso da elaboración dunha gramática galega da institución, que aínda hoxe non existe.

\subsection{A gramática como grande obxectivo do seu mandato}

Desde a súa fundación a RAG tiña como meta a elaboración dun dicionario e dunha gramática do galego. Así o explicitaba con clareza a circular que a Comisión Organizadora da "Asociación Iniciadora y Protectora de la Academia Gallega" da Habana dirixira ás persoas simpatizantes do proxecto o 24-6-1905 (cf. López Varela 2001: 121). Na primeira páxina do número 1, de 20-51906, do Boletín de la Academia Gallega informábase de que en xullo do ano anterior Manuel 
Murguía recibira un escrito procedente da Habana en que se comunicaba o acordo da Comisión de regulamento desa asociación iniciadora onde se lle encargaba a constitución da "Academia Gallega que ha de formar el Diccionario y Gramática de nuestra lengua". No número 2 do mesmo boletín, de 20-6-1906, insírese tamén na primeira páxina o “Reglamento de la Asociación Iniciadora y Protectora de la Academia Gallega", en cuxo artigo 2, punto 10, consta:

Constituir en el punto que mejor convenga de Galicia una Academia Gallega ajena a toda idea política y religiosa sin más carácter que el de dar unidad al idioma gallego por medio de la publicación de una Gramática y un Diccionario; estudiar nuestras ciencias; cultivar la literatura y las artes, inclusas las industriales; recoger nuestros cantos populares y nuestros monumentos arqueológicos, y realizando cuanto tienda a enaltecer y glorificar el buen nombre de Galicia.

Fica, pois, ben claro que na intención dos fundadores da RAG estaba a unificación escrita do idioma mediante a elaboración dunha gramática e tamén dun dicionario, obxectivo que constantemente se verá ratificado nos primeiros pasos da nova entidade. Se a respecto do dicionario a RAG recolleu moito material e mesmo conseguiu publicar 27 cadernos do seu inconcluso Diccionario gallego-castellano entre 1913 e 1928, no relativo á gramática case nada fixo no período anterior a 1936. Non conseguiu tampouco levar a cabo o obxectivo de elaborar unha gramática durante as dúas primeiras décadas de posguerra. Mais cando en 1960 Martínez-Risco accedeu á presidencia, fixo propósito firme de promover a elaboración desa gramática institucional, como ben afirma Franco Grande, na altura colaborador do presidente no seu gabinete de avogado da Coruña, quen xulga que "a idea máis cara a don Sebastián era a publicación da Gramática galega da Academia" e que "esa ía ser a grande aportación da súa presidencia", aínda que logo Piñeiro fixo que deixase "a unha beira o que sen dúbida era unha ilusión da súa vida" (Franco Grande 2004: 253-254).

Certamente, Martínez-Risco falecería sen ver publicada a gramática académica e durante todo o seu mandato na institución tivo de soportar a presión de non dar conseguido ese obxectivo, pois a ausencia dunha gramática, ou dunhas normas gramaticais mínimas que servisen de criterio unificador na escrita, tornábase clamorosa cando a recuperación literaria do galego atinxía xa un grao de desenvolvemento importante. Así o pon en evidencia, por exemplo, o membro de honra da corporación Rodrigues Lapa nas cartas que dirixiu a Fernández del Riego a propósito das sucesivas edicións da Estilística da Língua Portuguesa, que incluía exemplificación tirada de autores galegos; nunha carta de outubro de 1963, entre outras, manifesta algunhas cautelas para o incremento da presenza do galego perante a ausencia dun modelo lingüístico-gramatical claro e coherente: "Receio porém chamar a atenção para um idioma que não dispõe ainda de uma gramática aceitável. Insisto com vocês: isso é de uma urgência suprema" (Lapa 2001: 195).

Martínez-Risco non puido controlar o proceso de elaboración da gramática porque este estivo baixo o control de Piñeiro e do grupo de académicos de Galaxia que dominou a entidade. Aínda que aquel tamén facía parte dese grupo, que o levara á presidencia, porén nin era filólogo nin pertencía ao seu núcleo dirixente, de modo que a súa capacidade de influencia no ámbito gramatical era reducida e, alén diso, tiña de compaxinar a fidelidade ao grupo que o apoiara e a que en certo modo se debía coa posición arbitral que como presidente debía exercer, sen esquecer os vínculos co grupo de académicos coruñeses con que diariamente convivía, mesmo nas tarefas de goberno da institución. De todos os modos, durante o seu mandato a RAG conseguirá a aprobación e publicación das súas primeiras normas ortográficas e morfolóxicas (Real Academia Gallega 1971), o que en parte compensará unha certa sensación de fracaso que supuxo a imposibilidade de levar adiante unha gramática da corporación que, por outro lado, ningún outro presidente deu conseguido.

\subsection{A Comisión de gramática da Academia e as súas dificultades}

A preocupación pola falta dunha gramática da entidade non era exclusiva do presidente e existía tamén na nova corporación presidida por el. No AMR consérvase o guión da súa propia man da "Junta ordinaria del dia 11-dibre-1960", cun punto tres sobre asuntos de carácter interno para dar conta da proposta de nomeamento de "vocales de las Comisiones para la redacción de una 
Antología y una Gramática gallegas". Con data de "20 de San Martiño de 1960" figura no ARAG, nunha carpeta rotulada "Comisións para a creación dunha gramática e dunha antoloxía galegas. Correspondencia e informes", un escrito ao presidente, asinado por M. Banet Fontenla, en que comeza por afirmar que "[n]a derradeira xuntanza ordinaria da Academia foi tomado o acordo de facer un epítome ou síntesis da Gramática Galega e mais unha Antoloxía de traballos escolleitos". Para tal fin nomeouse unha "comisión encargada de redactar un compendio, o epítome, o librillo escolar de Gramática galaica", como diría máis tarde Manuel Rabanal nun dos seus artigos xornalísticos ${ }^{3}$. Tamén a pouco de entrar en funcións Martínez-Risco, a dirección da RAG visitara Compostela e contactara con Manuel Rabanal e Abelardo Moralejo, os catedráticos máis cualificados en materia lingüística, segundo comenta Piñeiro a Carvalho en carta de febreiro de 1961 (Alonso / Cuquejo / Fariña 2004: 37), na perspectiva de os implicar nas tarefas desa Comisión.

No mesmo arquivo e carpeta hai copia dun escrito do secretario da RAG, Vales Villamarín, datado a 26-1-61, en que convoca os membros da Comisión de gramática para unha sesión de constitución o día 18 de febreiro e unha nota manual, escrita con diferentes tipos de letra e de tintas, cos nomes dos membros da Comisión, formada pola Xunta de Goberno e os señores V. Risco, F. Bouza-Brey, Filgueira Valverde, V. Taibo, Iglesia Alvariño (marcado cunha cruz e entre parénteses o nome de Ramón Piñeiro), Chao Espina, Carvalho Calero, Abelardo Moralejo e Rabanal, estes dous últimos tipograficamente separados dos demais ao final da nota. Por tanto, o 18-2-61 constituíuse na RAG a Comisión de gramática e, falecido o 29-7-61 Iglesia Alvariño, Piñeiro ocuparía esa vacante, segundo tamén consta noutro documento existente no AMR. Carvalho, que máis adiante desempeñará un papel importante, nesa altura estaba totalmente agoniado pola dirección do Colexio Fingoi e pola elaboración da historia da literatura para Galaxia, de modo que posibelmente non asistise a esa reunión constitutiva, como el mesmo comenta en carta a Fernández del Riego de 13-2-61 (Carballo 2006: 193-194). V. Taibo, por súa parte, resístese a facer parte da Comisión de gramática coa desculpa dunha saúde precaria aos seus 76 anos, mais tamén por non ser gramático nin filólogo; a súa proposta é que os académicos con esa condición sinteticen e actualicen a gramática de Saco, segundo carta a Martínez-Risco de 3-3-61 (AMR) ${ }^{4}$.

Cara a finais do ano 1961 pouco ou nada se avanzara nos traballos da Comisión, como pon en relevo un escrito do secretario da RAG, de 13-10-61, en que se dirixe aos seus membros para lles solicitar que informen por escrito do traballo realizado. Case todos responden ao requirimento, como consta no ARAG, mais é de resaltar o escrito de Carvalho, de 20-10-61, en que afirma que o acordo fora crear unha subcomisión formada por Iglesia Alvariño, Filgueira Valverde, Abelardo Moralejo e Rabanal, e que era ela a encargada de realizar o traballo previo antes de interviren os demais membros da Comisión; algo similar se di no escrito de resposta de Chao Espina e doutros máis; o mesmo Chao, en carta-postal de 28-11-61 (AMR) ao presidente, fala de que é "unha vergoña" que a Galiza non teña unha gramática e de que é urxente dispor dun guión dela. A carta de Abelardo Moralejo leva data de 20-11-61 (ARAG) e nela di escribir tamén en nome de Rabanal, para a seguir indicar que a Comisión de gramática non se chegou a reunir e que eles non son os indicados para ese labor, que deberán facer persoas galegas.

Nun escrito de Bouza-Brey ao presidente, de 30-12-61 (ARAG) dá conta de que ese día se reuniron no Instituto P. Sarmiento, convocados por el propio, os "componentes de la Comisión nombrada para confeccionar un epítome de Gramática de la Lengua Gallega" P. Pedret, M. Rabanal, A. Moralejo, R. Piñeiro e F. Bouza-Brey, aos que se uniu A. Fraguas por se achar nese momento no mesmo lugar; e continúa a informar de que se acordou facer un esquema sobre o cal "se irían colocando las conclusiones que fuesen aceptadas" polos demais membros da Comisión ou polo resto de académicos e de que se barallaron outros nomes para esa, como J. L. Pensado, X. Alonso Montero ou R. Lorenzo, mais que se decidiu desbotalos pois nela "existen personas capaces de

${ }^{3} \mathrm{O}$ artigo leva por título "Primera carta a la Academia. Sobre variaciones o variantes del gallego" e fora publicado en La Noche de Santiago de Compostela en xaneiro de 1962; o recorte, sen datar, está no ARAG.

${ }^{4}$ Reiterará Taibo estes argumentos en carta (AMR) a Vales Villamarín de finais de 1962, que se pode interpretar como a súa renuncia definitiva a facer parte da Comisión. No sucesivo enténdese que as cartas e outros escritos do AMR e do ARAG son todos inéditos, a non ser que expresamente se indique o contrario; algunhas cartas do primeiro arquivo foron parcialmente citadas en Freixeiro (1994) mais na súa forma completa fican inéditas. 
realizarlo dada su sencillez", aínda que o problema era a falta de tempo; informa igualmente de que Cesáreo Saco tiña feito un epítome gramatical e de que fixeron a Piñeiro a encomenda de llo pedir para así o poderen estudar.

Os criterios e problemas de método a seguir para a elaboración desa gramática orixinaron outras dificultades e conflitos entre os membros da Comisión. Rabanal, na xa citada "Primera carta a la Academia...", afirmaba que unha gramática académica "tiene que aspirar a ser una especie de canon del mejor decir y no un inventario de peculiaridades coloquiales"; e ese artigo vai provocar algunhas reaccións de membros da Comisión, como a de Bouza-Brey, quen escribe a Martínez-Risco con data de 23-1-62 (AMR), e após comezar por se referir a unha intervención súa sobre o "epítome gramatical gallego" que provocou outra de Rabanal en que manifestaba que "mientras no hubiese trabajos monográficos respecto del gallego, esto es, estudios gramaticales sobre las distintas partes de la oración, no podría hacerse una Gramática en forma", opina que iso non era impedimento para a elaboración dun "compendio gramatical" como o que se perseguía, pois só había que procurar unha norma xeral e logo indicar en letra pequena as excepcións e variantes, a corresponder á RAG a capacidade de escoller entre varios criterios cando for preciso. Sobre iso falaran tamén en privado Bouza-Brey e Rabanal, mais este tratou o tema no artigo do xornal compostelán, o que orixinou as críticas dalgúns académicos e a petición de mediación a Martínez-Risco para preservar a confidencialidade das deliberacións; tamén alude Bouza-Brey na carta á esperada chegada de Piñeiro con noticias para poder realizar unha nova reunión.

Na resposta, de 29-1-62 (AMR), Martínez-Risco expresa a Bouza-Brey a opinión da Xunta de Goberno da RAG de a discusión pública a través de artigos nos xornais ser inconveniente e inoperante, alén de insistir en que se trataba de elaborar un "epítome" para uso de escolares que enchese o baleiro existente e non de realizar un labor exhaustivo que abranxese todas as variantes fonéticas, morfolóxicas e sintácticas; tamén mostra concordancia con Bouza-Brey na orientación que este lle quere dar á redacción da gramática, anímao a continuar a colaborar no encargo coa mesma dedicación e lémbralle que os membros "de esa subcomisión", cando terminaren o traballo, deberán sometelo á Comisión en pleno para ser estudado particularmente por todos, de modo que a responsabilidade científica deles e a da RAG ficará sempre garantida.

Con tal situación dentro dunha Comisión que achaba grandes dificultades para levar adiante o proxecto gramatical, vai aparecer un informe de Piñeiro que mudará o discorrer dos acontecementos e que na práctica deixará aquela sen funcións.

\subsection{O informe de Piñeiro e a paralización do proxecto gramatical}

O presidente da RAG vaise sentir presionado en dúas direccións opostas, pois, se por un lado algúns académicos como Chao Espina lle metían moita présa para avanzar rapidamente na elaboración da gramática, por outro Piñeiro vai intervir, en sentido contrario, para tentar frear ese proceso, facendo ver as grandes dificultades existentes. Así llo manifesta nunha extensa carta de 26-1-62 (en Freixeiro 1994: 207-209) en que rebaixa o optimismo inicial de Martínez-Risco e lle lembra a falta de competencia da RAG, e do propio presidente, na materia, en canto apela á súa responsabilidade á fronte da institución e promete o envío por iniciativa propia dun informe elaborado por el mesmo sobre o tema. Pouco tempo antes, en carta a Carvalho de 14-12-61 (en Alonso / Cuquejo / Fariña 2004: 37), Piñeiro falaba do seu recente nomeamento como membro da Comisión de gramática e do pequeno papel que lle correspondería desempeñar nela, o que non se compadecerá coa realidade dos feitos que logo se desenvolverían. Na realidade, en lugar de colaborar na realización da gramática, parouna; e, de calquera xeito, é evidente que a dirección dese proceso de (non-)elaboración da gramática estivo nas mans de Piñeiro, "home moi amigo de controlalo todo", como afirma o seu amigo Franco Grande (2004: 330). Tamén non torna fácil explicar a súa escolla para esa Comisión cando el aínda non era numerario da RAG ${ }^{5}$ e non tiña título de lingüista nin publicacións ao respecto.

\footnotetext{
${ }^{5}$ Sobre o ingreso de Ramón Piñeiro na RAG, que se substanciou co acto de recepción pública de 25-11-67, véxase Monteagudo (2007: 14-18).
} 
Como mostra a correspondencia, o certo é que Piñeiro foi falando cos diferentes membros da Comisión para os convencer da conveniencia de adoptaren unha posición prudente no tema gramatical; véxase, por exemplo, o que di a Carvalho en carta de 15-1-62: "Logo teño que me ocupar do choio da Gramática, do que penso falar longamente contigo na primeira ocasión que vaia por Lugo" (en Alonso / Cuquejo / Fariña 2004: 50). O mesmo Carvalho por estas datas estaba dando os últimos retoques á súa historia da literatura e achaba dificultades para unificar graficamente a obra, a se formular a posibilidade de el propio elaborar unha gramática galega, segundo afirma en carta de 5-3-62 a Fernández del Riego (Carballo 2006: 418-419). En contraste coa chamada á prudencia de Piñeiro, o académico Chao Espina, polo contrario, continuaba a pedir urxencia a Martínez-Risco, e á RAG, en carta de 7-2-62 (AMR): "Cuido que isto non pode ser; a Gramática non pode estar sin fazer por mais tempo". Catro días despois escríbelle outra carta (AMR) no mesmo sentido, aínda que reforzando os argumentos en prol da urxencia da gramática, en que el mesmo parece estar traballando xa: "Da vergoña que Galiza esteña no século XX sin Gramática”.

Nestas dúas posturas defrontadas que representan Piñeiro e Chao Espina, o presidente da RAG móstrase en principio de acordo co segundo, como lle transmite en carta de 14-2-62 (AMR): “Eu abundo nas túas inquedanzas ó respeito; entendo, coma tí, que é pra nós un deber de comprimento urxente dar ciume (sic) a ise proiecto, e agardo que ista acertada intervención túa sirva pra estimular a actuación dos colegas de Santiago". Nesta mesma misiva Martínez-Risco acusa recibo do envío por parte de Chao "do esquema gramatical" e agradécelle o interese que pon "na execución do proiecto do noso compendio de Gramática galega, como membro que eres da Comisión redactora". Chao elaborara un esquema de compendio gramatical, ou "Índice" segundo el propio dicía na carta anterior, seguindo "o mesmo método pedagóxico dos meus libros de Portugués", pois impartía aulas de lingua lusa na Coruña e era autor de obras como Curso de Lengua Portuguesa. Con efecto, na subcarpeta correspondente ao ano 1962 que figura no ARAG está o "Índice" de Chao, que ocupa cinco páxinas manuscritas e que é bastante parecido ao da súa gramática portuguesa antes citada (Chao 1958: 147-151).

No entanto, as ideas que van prevalecer finalmente son as de Piñeiro, que con data 17-262 envía ao presidente da RAG o informe, non solicitado, que lle prometera en carta anterior: “Velahí o informe encol da nosa situación lingüística, das suas necesidás máis inmediatas e das posibilidás da Academia pra lles facer frente axeitadamente" ${ }^{\prime 6}$. Martínez-Risco fala dese informe a Antonio Fraguas en carta de 5-3-62 (AMR) e nela afirma que o vai someter á opinión de cada un dos membros da Comisión e que logo convocará unha Xunta extraordinaria para acordar o que for máis conveniente. Tamén lle resume o contido do informe dicindo que Piñeiro propón "a ouservancia de tres etapas: estudo dos feitos lingüísticos, é decir, da multiplicidade polifórmica do galego; unificación selectiva, e redacción da Gramática"; xulga igualmente Piñeiro que a primeira debe ser sometida aos lingüistas da RAG e que as outras dúas son competencia desta.

O informe de Piñeiro, que está custodiado na mesma subcarpeta do ARAG que o índice de Chao, ocupa catro páxinas mecanografadas con letra apertada. Hai tamén nese arquivo copias dos escritos de envío del aos membros da Comisión de gramática e respostas dalgúns destes, como o propio Chao, que dá a máis longa, en cinco páxinas manuscritas, para manifestar no fondo a súa discrepancia con Piñeiro e urxir a elaboración da síntese gramatical sen máis dilacións. Ou Carvalho, que mostra a súa conformidade coa primeira fase proposta por Piñeiro, aínda que deixa as outras nas mans das persoas que utilizaren o galego por seren elas as que deberán determinar a súa forma escrita. Nunha carta de 1-6-62 Piñeiro comenta a difusión do seu informe con Carvalho, anúncialle que lle enviou copia a Pensado porque o considera "a meirande autoridade romanística con que contamos hoxe os galegos" e que este lle mostrou a súa conformidade, o que lle deu "bastante tranquilidade"; tamén se alegra de Carvalho coincidir con el na primeira fase e de que por medio do seu informe "a Academia tome plena concencia do problema e das suas dificultás" (en Alonso / Cuquejo / Fariña 2004: 57-58). Bouza-Brey, por súa parte, escribe a Martínez-Risco (ARAG) con data de 30-3-62 para lle dicir que Fraguas lle devolvera o informe de Piñeiro alegando que el non era lingüista e para lle comunicar, cun certo ton sarcástico, a súa decisión de causar baixa na Comisión de gramática que presidira.

${ }^{6}$ Pode lerse a carta completa de remisión en Freixeiro (1994): o informe anexo de Piñeiro non se acha no AMR, mais si no ARAG, de onde foi reproducido e extensamente anotado por Santamarina (2009). 
É evidente que Piñeiro non confiaba na capacitación lingüística das persoas galegas cun certo grao de compromiso co galego e que estaban dispostas a traballaren na elaboración da gramática, incluído o seu amigo Cesáreo Saco, que xa tiña elaborada unha síntese gramatical. En troca, parece confiar en exceso no traballo que puideren facer persoas galegas afastadas do país ou non galegas con preparación técnica sobre a materia, mais con carencia de interese ou compromiso coa tarefa a realizar. É ilustrativa ao respecto unha carta a Carvalho, de 1-11-62, onde se mostra confiado en que a chegada a Compostela dos profesores Diego Catalán e Clavería supoña que "os nosos estudos lingüísticos comenzarán a marchar por bó camiño", de maneira que se inicie unha"verdadeira escola de Lingüística galega, que tanto se bota de menos na nosa cultura"; e onde tamén o postula para a cátedra de Lingua e Literatura Galegas que deberá de ser convocada no futuro próximo (en Alonso / Cuquejo / Fariña 2004: 63). Con todo, Piñeiro pensa en Carvalho para ser a referencia da literatura galega, mais non así da lingua, aínda que faga parte da Comisión de gramática e asista ás súas reunións en ocasións. As teses de Piñeiro, que exerce unha función tutelar sobre a RAG a pesar de aínda non ser en 1962 membro numerario, acabarán por se impor e a gramática non se vai levar a cabo.

No fondo, non é que Piñeiro estivese en contra da elaboración desa gramática; o que acontecía é que non confiaba na preparación técnica dos académicos. Así, en carta de 2-1-62 a Pensado, propuxéralle que fose el quen a fixese por ser o romanista galego con máis preparación científica, e por Abelardo Moralejo e Rabanal, a pesar da súa competencia, non seren galegos nin dominaren a lingua (en Alonso / Abal / Cillero 2009: 41-42). No entanto, Pensado rexeitará a oferta de Piñeiro aludindo ás súas responsabilidades universitarias afastadas da realidade lingüística galega, como se deduce doutra carta que lle dirixe Piñeiro con data de 4-2-62, onde Ile fala da "elaboración da Gramática Normativa Galega" e lamenta que Pensado non estea destinado en Compostela; tamén recoñece a necesidade da gramática e comprende a urxencia da RAG, mais opina que esta "debería dar un paso previo: promover o estudo de algúns problemas fundamentás da nosa realidade idiomática viva", que son a "determinación das zonas e caraiterísticas dialectás do galego" e o "estudo e ordenación do noso verbo" —ofrece varios exemplos de polimorfismo na conxugación verbal-, mostrándose inclusive partidario de convocar un concurso ao respecto (en Alonso / Abal / Cillero 2009: 43-45). En carta de 26-2-62 Piñeiro transmite a Pensado máis información sobre o proceso en que está a RAG, a ratificar así a súa dirección e control deste, e deixando constancia do peso da súa opinión na entidade: "Semella que están dispostos a modificar o programa de traballo" (en Alonso / Abal / Cillero 2009: 46).

O informe de Piñeiro puxo fin na práctica ao proxecto gramatical e a Comisión de gramática non resultou, pois, operativa, aínda que para o 16-12-62 se convoca unha Xunta Extraordinaria da RAG coa seguinte orde do día: “Lectura y estudio de los dictámenes presentados por los señores Académicos encargados de informar acerca de la proyectada edición de un manual de Gramática gallega"; como os ditames eran en xeral favorábeis ao informe de Piñeiro, é posíbel que o acordo a que se puido chegar fose deixar en suspenso as urxencias gramaticais. Algúns membros da Comisión, con todo, non daban enviado o seu ditame sobre o informe de Piñeiro, pois no ARAG hai copia dun escrito do secretario, de 20-10-62, a Filgueira Valverde en que o insta a enviar ese ditame que xa lle solicitaran en dúas ocasións anteriores e outra copia dun escrito similar coa mesma data a V. Risco; e aínda figura copia doutro escrito de Martínez-Risco a Filgueira en que lle roga que envíe o ditame por ser importante a súa opinión e que asista á reunión que para ese efecto se iría celebrar o día 16. Como xa se suxeriu, talvez nesta reunión se acordase dar por válido e definitivo o informe de Piñeiro.

O caso é que, aínda seis anos despois, en 1968, escribe o presidente que a RAG está orientada cara á "necesaria redaición dunha Gramática do galego" (S. Risco 1968: 25), tarefa que el non verá realizada. Tivo de se contentar coa aprobación dunhas breves e incompletas normas ortográficas e morfolóxicas xa pasado o ecuador do seu mandato presidencial. Isto foi o que lle permitiu o núcleo de Galaxia dominante na RAG, capitaneado por Piñeiro, quen mesmo antes de formalmente ingresar como académico numerario o 25-11-67, xa tiña en mente unha rápida solución nese sentido, pois así o deixa translucir no discurso pronunciado ese día (Piñeiro 2007: 79-86). Certamente, pouco máis de dous anos despois, a inicios de 1970, aprobáronse as normas ortográficas e en 1971 as morfolóxicas. 


\section{A PRODUCIÓN GRAMATICAL NA DÉCADA DE 60}

Após a interrupción do proceso de elaboración de gramáticas que supuxo a guerra de 1936, con dúas décadas ermas en traballos dese teor, na década de 60 vaise reemprender esa tradición coa publicación de dúas novas gramáticas, unha que contou co apoio solidario do grupo de Galaxia, a de Carvalho Calero, e outra que Leandro Carré levou a cabo co seu traballo solitario. Ambos eran membros da RAG, mais en canto o primeiro tiña o recoñecemento xeral pola súa condición de filólogo e a axuda explícita do núcleo dominante da corporación, o segundo non gozou da mesma consideración nin colaboración, a pesar de facer parte da Xunta de Goberno da entidade. Con todo, as dúas obras xorden como gramáticas de autoría individual e ningunha delas, por tanto, foi asumida como propia da institución académica, a pesar de ese ser talvez o propósito de Carré, que inclusive chegou a preparar unha síntese gramatical con algunha expectativa nese sentido en finais da década. Esta síntese ficou inédita até a actualidade.

\subsection{O traballo solidario de Carvalho Calero}

Piñeiro, que asume certamente un compromiso persoal coa defensa do galego (González 2006), após ver fracasada a opción de Pensado como autor da gramática académica, dirixe a súa atención cara a Carvalho, que xa publicara a súa historia da literatura, mais para o animar a que leve adiante o proxecto de elaborar unha gramática da súa exclusiva autoría dentro do proxecto editorial de Galaxia, non para facer a gramática da RAG. Na realidade, como informa Villanueva Gesteira (2015: 223-228), a editora viguesa e o seu director xa andaran previamente "á procura dun lingüista", para o que contactaran sucesivamente con Aníbal Otero, Aquilino Iglesia Alvariño, Isidoro Millán González-Pardo e Ramón Lorenzo; foi só perante a negativa destes cando se dirixiron a Carvalho Calero.

O profesor ferrolán vai asumir esa nova empresa con esforzo e disciplina, como máis unha angueira no seu compromiso persoal de traballar polo galego, de modo que en finais de 1963 Galaxia xa publicitaba unha gramática de Carvalho que este aínda non comezara, como se desprende dunha carta súa a Del Riego de 22-12-63:"Xa que anunciades a miña Gramática teréi que pensar en facela. Conviría que me mandaras todo o que teñas de antecedentes; pois eu carezo de libros de filoloxía galega" (Carballo 2006: 379); con todo, noutra carta ao mesmo destinatario de inicios de 1964 aínda afirma que "[d]a Gramática polo de agora non hai máis que darlle voltas na cabeza. É horrible" (Carballo 2006: 383); mais a primeiros de marzo, após terminar o encargo dunha breve antoloxía de literatura galega, xa só pensa en se concentrar na elaboración da gramática (Carballo 2006: 384-387). E na correspondencia dese ano e do seguinte con Del Riego tanto lle pide libros e artigos de consulta como se lamenta das súas moitas ocupacións e do escaso tempo que lle deixan para se ocupar da gramática. Por iso Piñeiro, en carta de 4-2-64, xa Ile dicía: "Alégrome ben de que vaia madurecendo na tua mente o plan da futura Gramática" (en Alonso / Cuquejo / Fariña 2004: 76); e noutra de 4-5-65 móstralle a súa coincidencia coa "absoluta prioridade da Gramática a calquer outro traballo" (en Alonso / Cuquejo / Fariña 2004: 90).

Por esas datas Carvalho estaba totalmente centrado nesta obra e agoniado coa súa próxima finalización, como mostra nunha carta a Del Riego de 31-5-65 en que fala de que ten materiais para un segundo libro sobre Pondal, mais engade: "Pero ¿quén pensa niso coas triganzas da Gramática?"; nela mostra tamén a preocupación polo resultado "porque a Gramática non pode sair tan ben que xustifique o tempo empregado en compoñela" e porque non se poderá igualar coa gramática catalá de Badia, aínda que esa tampouco era a intención con que afrontou un proxecto que outros non quixeron facer por consideraren preferíbel "non facer nada" (Carballo 2006: 394-396). Non se atrevía nesa mesma carta a pór data para o final dunha tarefa para a cal continuará a se documentar, recibindo a obra de Badia e a gramática portuguesa de Tavani (carta a Del Riego de 2-7-65); e tamén fai propósito en cartas sucesivas de avanzar decisivamente nela, de modo que nos primeiros meses de 1966 xa comeza a enxergar o final do túnel, sen por iso reducir a súa dedicación ao proxecto, a renunciar mesmo ao descanso estival, como manifesta en carta de 16-7-66 (Carballo 2006: 411-413). Nesta mesma carta comenta a Del Riego que 
"todo o meu traballo, mesmo as miñas lecturas, están orientadas á Gramática de cuia posesión demoníaca desexo me liberar", obxectivo que cumprirá axiña, pois nas misivas sucesivas xa vai dando conta do proceso de corrección de probas.

Finalmente, a Gramática elemental del gallego común de Carvalho Calero sairá do prelo en Galaxia no ano 1966, coa seguinte nota final: "Este libro terminó de imprimirse en los Talleres Gráficos de "FARO DE VIGO", Colón, 28-30, el día 5 de noviembre de 1966". En carta do autor a Del Riego, de 22-11-66, comunícalle que recibiu a gramática e que "resulta un fremoso volume". Con todo, non se liberará por moito tempo do traballo gramatical, pois en xuño do ano seguinte xa manifesta estar a traballar para unha nova edición da obra (Carballo 2006: 433). E non deixa de saudar a concorrencia doutras gramáticas galegas nese ano 1967: “Vin a Gramática de Carré, e merquéina. Agora agardo que chegue por eiquí a de Saco, que tamén adquiriréi. ¡De súpeto, puxémonos moi ben de Gramáticas!" (Carballo 2006: 440).

Naquela altura os antigos membros da Comisión de gramática da RAG, entre os que tamén se contaba Carvalho, estaban ocupados en ditaminaren os informes de Carré, presentados en 1965, sobre as terminacións -ción/-zón e sobre as grafías ao/ó/ô, ambos depositados no ARAG. Precisamente cando Rabanal emite o seu ditame a través das páxinas dun xornal compostelán sobre este último aspecto, a mostrar a súa preferencia por $a$, tamén aproveita para saudar a saída do prelo da gramática de "Ricardo Carballo, gramático cabal y bien informado", que "ha venido a llenar un hueco que urgía llenar"7.

O proxecto gramatical de Galaxia e de Carvalho non só non se detén en 1966 como continúa até 1979, con sucesivas reedicións revisadas e ampliadas que supoñen a constante actualización dunha obra que comezou sendo a gramática de Galaxia feita por Carvalho para terminar por ser a gramática deste publicada por Galaxia. El deu ao prelo esta obra após ter finalizado a historia da literatura, ambas as obras a faceren parte do proxecto editorial e político-cultural de Galaxia seguindo o deseño ideolóxico de Piñeiro e coa inestimábel colaboración operativa de Fernández del Riego. Mais a gramática de Carvalho tamén obedece en parte ás novas necesidades da lingua galega, incorporada ao ensino universitario, e ao labor docente e investigador do seu autor, que se encarga das aulas de galego no ensino superior e que ao mesmo tempo se está a preparar para optar á primeira cátedra de Lingua e Literatura Galegas da USC. El mesmo o explicita: "É unha gramática concebida como instrumento de traballo nas clases, nas aulas de Língua Galega que estavan ao meu cargo" (en Fernán-Vello / Pillado 1986: 175). Fala a seguir das modificacións que foi introducindo nas distintas edicións da súa gramática, cuxa evolución "segue unha liña absolutamente recta", segundo el, de acordo co avanzo dos tempos, co debilitamento do "réxime imperante" e co incremento da "liberdade con que un profesor pode expresar a sua doutrina a propósito da língua galega". Recoñece que as diversas edicións da obra se fan de acordo con esas circunstancias, mais rexeita categoricamente que a sétima edición de 1979 "supoña unha rectificazón da primeira edizón publicada en 1966", a insistir na prudencia e precaución que exixía a evolución da situación política (en Fernán-Vello / Pillado 1986: 177).

Mais se as anteriores edicións da obra podían ser asumidas polo proxecto cultural e lingüístico de Galaxia, a última viña a supor de facto a ruptura do autor co que representaba Piñeiro, para avanzar nunha vía reintegracionista en que este definitivamente non acreditaba. Carvalho terminaba o prólogo á sétima edición anunciando aínda novos pasos nesa vía en vindeiras edicións: "La necesidad de una reintegración del gallego en su mundo originario se nos aparece más clara, y ello nos impondrá en el futuro inevitables retoques" (Carballo 1979: 12). Mais xa non habería novas edicións da gramática; e a intensa e prolongada relación de Carvalho con Galaxia irá minguando até a extinción, a minguar tamén a solidariedade do grupo editorial con esa derradeira versión da Gramática elemental del gallego común que tanto apoiara anteriormente. De todas as formas, non cabe dúbida de que esta obra foi produto do esforzo solidario do seu autor co proxecto galeguista de Galaxia, que, por súa vez, lle prestou toda a súa solidariedade no plano material e humano.

\footnotetext{
${ }_{7}^{7}$ Véxase "Nebulosa. Consulta y buena noticia", artigo asinado co pseudónimo "R. del Camino" en La Noche e cuxo recorte figura no ARAG sen datación.
} 


\subsection{O labor solitario de Carré Alvarellos}

Pouco tempo despois da aparición da primeira edición da gramática de Carvalho, tamén vai publicar Carré Alvarellos a súa Gramática gallega, sen contar cos apoios que tivo a de Carvalho, no mesmo ano 1967 en que Gráficas Tanco tira do prelo en Ourense a segunda edición da gramática de Saco Arce que leva o mesmo título. Así o comenta Piñeiro a Basilio Losada en carta de 31-10-67, a valorizar pexorativamente o contributo do autor coruñés: "Agora reeditouse a Gramática gallega de Saco y Arce, e o Carré editou a súa —ben maliña por certo-" (Piñeiro / Losada 2009: 620). Carré posuía unha escasa preparación filolóxica, de modo que o seu contributo á lingüística e á gramática galega debe medirse basicamente pola capacidade de crear ferramentas de utilidade para a fixación do galego escrito. En tal sentido, Carré tivo a ousadía de enfrontar a elaboración de materiais filolóxicos — gramáticas e dicionarios- que outras persoas non tiveron, sendo "o elemento motivador ou o revulsivo" para a emerxencia doutros estudos gramaticais e propostas estandarizadoras (Maceira 2014: 517). As súas iniciativas gramaticais pretenderon encher baleiros que as entidades máis directamente involucradas — nomeadamente a RAG - non daban cuberto e que era urxente facer, seguindo as directrices marcadas nos textos programáticos do nacionalismo irmandiño, primeiro, e logo na posguerra de acordo coas demandas de persoas implicadas na recuperación do galego.

As inquietudes filolóxicas de Carré foron constantes durante a súa vida, a pesar de non posuír unha formación académica ao respecto, feito que compensaba con moita dedicación e entusiasmo xa desde novo. Percorreu todo o país na procura de información lingüística, mais tamén sobre costumes e tradicións, alén de se interesar polas fontes bibliográficas existentes; e posuía igualmente coñecementos teóricos e prácticos do portugués que probabelmente superaban o promedio dos seus compañeiros de corporación académica e que se alimentaban coa relación directa con personalidades da cultura portuguesa, como explica el propio nun escrito enviado á RAG, após deixar constancia de ter estudado o idioma galego desde a súa infancia e de levar percorrido todo o país na procura das súas tradicións e costumes ${ }^{8}$.

Na primeira parte do século realizou traducións de varios autores (Maceira 2014: 521), de modo que axiña tivo ocasión de reparar na falta de ferramentas fundamentais para o cultivo literario do galego, nomeadamente gramáticas e dicionarios. Por iso o movemento nacionalista irmandiño, de que Carré fixo parte desde o primeiro momento, se marcou o obxectivo de promover tales recursos para o idioma e o noso autor tentou colaborar na súa posta en práctica. Deste modo, das dúas gramáticas que se encadran no período das Irmandades da Fala (19161931), a primeira é a da súa autoría: un Compendio de gramática galega asinando como "R. A." e saído do prelo en 1919. Esta pequena síntese é a primeira gramática escrita en galego e tamén é a primeira concibida dunha forma non diglósica. Carré aínda se atreveu con outra das grandes tarefas filolóxicas pendentes: a elaboración dun dicionario galego, que culminou no inicio da década de 30 coa edición do segundo volume (Carré 1928 e 1931) e que pouco despois reeditou conxuntamente (Carré 1933).

Na posguerra Leandro Carré continuou a cultivar a súa afección filolóxica e o estudo de temas relacionados coa lingua galega, a se manter constante o seu interese por ela tanto no relativo á súa situación presente, canto desde a perspectiva histórica9. Pasados os anos máis duros da represión franquista Carré, xa membro de número da RAG, empéñase en que esta institución poida dispor das ferramentas imprescindíbeis para a recuperación literaria do galego e, nese sentido, ofrece o seu traballo e o seu labor precedente na procura de apoio institucional e aval de prestixio para a súa propia obra filolóxica. Arredor de 1950 o Centro Galego de Bos Aires pide un informe a Otero Pedrayo sobre a posibilidade de elaboración dun dicionario galego e na resposta ${ }^{10}$ este menciona os máis relevantes e non cita o de Carré, feito bastante significativo da soidade en que este tivo de levar adiante os seus proxectos filolóxicos. Maceira afirma que

\footnotetext{
${ }^{8}$ Texto mecanografado en 6 folios e custodiado no ARAG que leva por título "Objeciones a las respuestas relativas a mi proposición de 1 de mayo de 1965 acerca de temas filológicos", do que se falará a seguir.

${ }^{9}$ Para máis información sobre o labor de Leandro Carré Alvarellos en prol da lingua, da súa reivindicación histórica e da normalización social, véxase Maceira (2014: 494-511).

${ }^{10}$ Esta carta de Otero ao Centro Galego de Bos Aires, de 8-1-50, está depositada nos arquivos da Biblioteca desa entidade.
} 
as propostas de Carré dentro dunha entidade totalmente controlada polo grupo de Galaxia a partir dos anos 50 tiñan sempre como resposta "un clamoroso silencio" e, a pesar diso, el nunca se rendeu e mesmo "propuxo a súa gramática co fin de desencadear a reflexión que resolvese crear unha oficial e protestou contra as manobras dilatorias na confección dun dicionario e mais dunha gramática da Academia"; e aínda pouco antes de morrer "esixía que a xunta xeral da RAG afrontase a necesidade de editar unha gramática, segundo os estatutos da institución, que partise duns criterios tradicionais e que combatese a castelanización do galego" (Maceira 2014: 545-546).

Nunha carta de Piñeiro a Carvalho, de 12-6-61, alúdese á falta de apoios de Carré na altura, "coa única esceición de Banet" (en Alonso / Cuquejo / Fariña 2004: 43). Xa pouco tempo antes, en carta de 3-3-61 a Martínez-Risco (AMR), V. Taibo rexeitaba facer parte da Comisión de gramática da Academia co argumento de non ser experto na materia como outros académicos que si o eran e que coñecían ben o idioma; mais entre eles non cita, curiosamente, Leandro Carré, a pesar de este ser autor na altura dun compendio gramatical, dun dicionario e dunha gramática aínda non publicada, mais que sometera a xuízo valorativo da Academia con resultado positivo, como mostra un informe de Martínez-Risco ao presidente da RAG de 7-3-56 (AMR). Anos máis tarde, nunha carta a Basilio Losada, de 22-3-70, Piñeiro explica que, para evitar a participación de Carré na elaboración das normas ortográficas da Academia, ideou a artimaña de crear "unha Comisión espontánea de académicos" (Piñeiro / Losada 2009: 796). Mais, como se acaba de ver, a desconfianza no valor científico dos traballos filolóxicos de Carré estaba bastante estendida entre os académicos e, por tanto, non era exclusiva de Piñeiro. Dela participaba tamén o portugués Manuel Rodrigues Lapa, quen por finais de 1952 dicía por carta a Fernández del Riego que "[n]ão se pode fazer cultura pactuando com o que é medíocre e francamente ruim" (Lapa 2001: 70), a se referir ao dicionario de Carré que ía camiño da terceira edición. Certamente, o escaso rigor académico das propostas lingüísticas deste autor non era un bo aval para seren tomadas en consideración.

A pesar desa marxinación, Carré estivo a traballar nas décadas de 50 e 60 na elaboración dunha gramática completa do galego e, ao mesmo tempo, fixo propostas sobre a codificación do idioma, tanto enviando informes á RAG en prol de -zón e de ao como ao "Seminario didáctico da língoa galega" que no verán de 1966 se reuniu en Vigo. Nas súas propostas lingüísticas sempre está presente a idea de construír un galego máis auténtico e menos castelanizado que, sendo moderno e actualizado, manteña a fidelidade ás súas raíces históricas e evite na súa forma culta as deturpacións da fala popular descoidada, como ben explicita nas "Objeciones a las respuestas relativas a mi proposición..." (ARAG).

Deixando de lado a síntese gramatical publicada en 1919, Carré estivera a traballar nos inicios da década de 50 nunha gramática que presentou ao Premio Otero Pedrayo convocado polo Lar Gallego de Caracas, escrita en galego co título de Gramática galega e que obtivo o terceiro premio (Maceira 2014: 518). Segundo este mesmo investigador, a obra foi presentada polo autor á RAG en 1955 para que esta emitise o correspondente informe a respecto do seu valor científico, presumibelmente coa intención de que esta entidade a recomendase ou inclusive a asumise como obra de referencia. Aínda que Maceira afirma que os académicos "nunca trataron o tema oficialmente", porén cómpre indicar que se nomeou unha comisión ao respecto e que esta emitiu informes particulares dos seus membros e un informe final, segundo documentación existente no AMR. No mesmo arquivo figura copia dun escrito da RAG, asinado por Manuel Casás como presidente e con data de 22-4-55, en que se comunica a Martínez-Risco o acordo da Xunta de Goberno do día 16 do mesmo mes "de que por la Junta de Goberno se designasen los Numerarios que habrían de dictaminar respecto de la Gramática Gallega que el señor Carré Alvarellos presentó a informe de la Academia". De todos os modos, o asunto non foi tratado precisamente con moita dilixencia, pois non será até o 20-11-58 cando o secretario da RAG comunique por escrito a Martínez-Risco que xa recibiu todos os ditames dos membros da comisión. Após a reunión desta, debeu aprobarse un "Informe" que figura sen datación no AMR e que foi escrito por Martínez-Risco; aínda que está sen datar, debe de ser de finais de 1958 ou inicios de 1959, e comeza por dicir que a gramática que Carré someteu a ditame "constituye, a juicio de esta Corporación, un trabajo muy estimable". 
Con este informe parece finalizar o percurso académico desa Gramática gallega — tal como figura na correspondencia citada — de Leandro Carré, que posibelmente fose a tradución para o castelán do orixinal premiado no concurso caraqueño, segundo Maceira (2014: 518) "ampliado, mellorado con reflexións propias e doutros filólogos como Joseph M. Piel ou Ernst Zellmer". Non achamos moita máis información dela até que sae do prelo co mesmo título en 1967, editada pola Imprenta Moret da Coruña e en cuxo "Prólogo" o autor comeza por afirmar que escribira a obra orixinariamente en galego, mais que algúns amigos, filólogos estranxeiros e outras distinguidas personalidades lle pediran e aconsellaran que a publicase en español para así conseguir unha maior difusión e facilitar o coñecemento "de nuestra lengua" ás persoas interesadas nela (Carré 1967: 7). A obra segundo Maceira (2014: 518) "tivo un grande éxito e unha divulgación internacional moi importante", a se basear en declaracións do propio autor de agosto de 1968 afirmando que a edición estaba case vendida nun ano e na correspondencia que se conserva no seu arquivo particular; mais non chegou a ser reeditada.

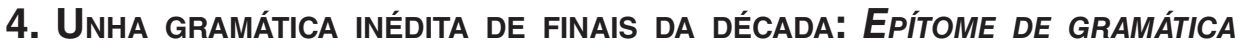 GALEGA}

Próxima a finalizar a década de 60, aínda Martínez-Risco continuaba coa idea de elaborar unha gramática da RAG. Maceira (2014: 519) informa de que na reunión da Xunta de Goberno de 152-69 se tomou o acordo de encargar a Carré "un epítome de Gramática gallega, con un vocabulario anexo, para someter á consideración da comisión académica correspondente", expresión literal que procedería dunha carta da RAG a Carré asinada polo presidente e o secretario, e que se acharía no arquivo particular daquel. Consultada a acta da Xunta de Goberno dese día, nela constan como asistentes Martínez-Risco, Carré Alvarellos e Vales Villamarín, e entre os acordos tomados figura o seguinte: "Asimismo se acordó encomendar a don Leandro Carré Alvarellos la presentación de un epítome gramatical gallego, con su vocabulario, para que la Academia pueda hacer uso de él en su oportunidad". Con efecto, Leandro Carré realizaría nese período unha versión sintetizada da súa gramática a que puxo por título o mesmo que a RAG estivera barallando para o seu proxecto durante os anos iniciais da década, Epítome de gramática galega. $\mathrm{O}$ exemplar mecanografado que coñecemos está depositado no AMR, mais nas carpetas do ARAG que xa se citaron non aparece copia deste texto nin documentación ao respecto.

\subsection{Autoría e datación}

O exemplar é un texto mecanografado, sen indicación de autoría e sen datar, que con certeza debe ser de Leandro Carré Alvarellos por se tratar dunha síntese da Gramática gallega deste, tanto polo modelo xeral de lingua que propón canto pola coincidencia de definicións e exemplos, ben como por certas similitudes co compendio de 1919 do mesmo autor. Porén, nin no AMR nin no ARAG demos con ningún documento en que expresamente conste que é Carré o autor do texto. A referencia máis explícita provén dunha carta do propio Carré a Martínez-Risco, datada a 29-10-69 e custodiada no AMR, onde consta a posibilidade de dar a obra ao prelo:

Como nas conversas que seguiron na xuntanza do domingo aludíuse ao proxecto da imprentazón do Epítome de Gramática Galega, vou enviarlle as copias das tres ou catro respostas que temos encol dela, e por se se tratar na próisima xunta xeral dese asunto, rógolle me envíe un escrito decindo por qué me foi encarregada por vostede a redaizón, e ouxetos que se pretenden con ela.

Tamén non localizamos este escrito do presidente, se é que existiu, nin esas copias das respostas que lle tería enviado Carré, pois nese momento aquel estaba destinado en Xirona por un curto período de tempo e as posibilidades de a documentación se perder eran certamente maiores. Mais da carta de Carré pode desprenderse con clareza que recibira realmente o encargo de elaborar ese epítome e que nesa altura xa estaba terminado e mesmo fora obxecto dalgún informe particular; e talvez igualmente do informe conxunto dunha comisión nomeada para tal propósito, segundo se deduce dun escrito de Filgueira Valverde ao presidente, de 4-2- 
70, en que lle comunica o acordo dos membros da "Ponencia" de "[r]edactar o informe conxunto encol do libro da 'Gramática'"' (ARAG), que con certeza se refire ao Epítome de Carré. Mais o que non se substanciou foi esa posibilidade de "imprentazón" por razóns que non se achan explicitadas en ningún documento que coñezamos.

Canto á autoría, non existen, pois, dúbidas a respecto de o texto ser escrito por Carré, que o elaboraría a partir da súa gramática de 1967 ao recibir en febreiro de 1969 ese encargo por parte da Xunta de Goberno da RAG, a que o propio Carré pertencía como tesoureiro. O epítome ficaría esquecido por o núcleo dominante da entidade, liderado por Piñeiro e Galaxia, non partillar os seus criterios normativos. Segundo a interpretación de Maceira (2014: 519), aquel encargo tiña por obxectivo "dispor dun material que contrapoñer a outras gramáticas como a de Carballo Calero" e as "liñas de actuación do grupo de numerarios afíns ao proxecto da Editorial Galaxia, dentro da Academia, ían destinadas á marxinación de Carré e a prescindir das súas propostas normativas". Martínez-Risco parecía apoiar o labor gramatical deste, mais ao mesmo tempo era un home de Galaxia e seguía as directrices de Piñeiro. Como presidente, tentaría manter un difícil equilibrio: contentar o seu colaborador Carré sen contradicir estas.

Non era Carré, certamente, filólogo nin tiña unha especial preparación científica na materia, mais tomou iniciativas e levou adiante proxectos gramaticais que outras persoas, talvez máis preparadas, non puideron ou quixeron emprender. O Epítome de gramática galega, posibelmente de 1969 , foi o derradeiro deles.

\subsection{Descrición e valorización}

A síntese gramatical consta de 45 folios de $27 \mathrm{~cm}$. de longo por $22 \mathrm{~cm}$. de largo mecanografados por unha cara a duplo espazo e numerados manualmente na marxe superior dereita de cada páxina; a última está invertida e vai numerada con "65", posibelmente por erro, en lugar do " 45 " que lle correspondería. Non contén máis indicacións que o título e unha nota de rodapé na segunda páxina relativa á grafía histórica $<\mathrm{j}>$.

A respecto da estrutura, organiza os contidos en catro partes, como xa se indica ao inicio, que denomina "Analoxía", "Sintase", "Prosodia" e "Ortografía", moi descompensadas canto á extensión, pois a primeira ocupa 33 páxinas, en canto a "Prosodia" apenas chega á media páxina, por unhas sete de "Sintase" e cinco de "Ortografía". Na "Analoxía" inclúe nocións de fonética e toda a morfoloxía: "artigo", "nome", "adxetivo", "pronome", "verbo", "adverbo", "preposizón", "conxunzón" e "interxeizón"; a maior parte do espazo está dedicado á conxugación verbal, en que se inclúe, alén dos verbos regulares, irregulares, auxiliares e reflexivos, a "conxugazón dos verbos con pronomes enclíticos"; esta estruturación da obra é bastante similar á que ten o Compendio de 1919, que por súa vez bebe directamente da gramática de Saco Arce. As outras tres partes do Epítome coinciden coas de Saco, en canto no Compendio se inclúen algunhas nocións de sintaxe e prosodia na epígrafe "Algunhas regras de escritura" e se mantén unha parte final intitulada "Regras ortográficas". Por súa vez, a Gramática gallega de 1967 presenta diverxencias organizativas na sección inicial para coincidir nas demais. Hai bastantes coincidencias en xeral entre as catro obras e, por tanto, tamén entre as dúas sínteses gramaticais de Carré, a de 1919 e a de 1969.

Canto ao modelo normativo que propón este derradeiro traballo gramatical de Carré, cómpre subliñar a existencia dunha substancial liña de continuidade cos anteriores, con algunhas modificacións tendentes á harmonización das solucións gráficas e morfolóxicas. No Compendio de 1919 fai un uso maioritario da terminación -ción, ao lado da solución minoritaria -zón, ambas a alternaren inclusivemente nunha mesma palabra (oración e orazón, terminación e terminazón etc.) e que definitivamente unificará en -zón após ter presentado en 1965 aquel informe á RAG en que propuña que esta a adoptase como propia; así, o Epítome iguala todos os casos en -zón, salvo uns poucos que se poden xulgar como descoidos ou erros. No outro informe propuña ao(s) para a unión da preposición e o artigo masculino, solución xa presente en 1919 e que mantén en todas as (re)elaboracións posteriores, incluída a última do Epítome; non acontece así co pra de 1919 , que se regulariza en para nos 60 , nin co plural tipo varós do primeiro traballo, que torna 
varóns ou cans no último, do mesmo modo que vocás ou ordinás viran en vocaes ou ordinaes. Mantéñense, iso si, en todos os casos certos usos gráficos como o do acento circunflexo ( $\hat{a}$, irmâ, lêr), do apóstrofo (co'ela, co'este, c'unha) ou do trazo (pol-o ben), o que leva a Alonso Pintos situar o autor nas "concepcións ortográficas de certo autonomismo que, na posguerra, continuaba escribindo segundo as coordenadas gráficas e grafotácticas do período 1916-1936"; tamén é certo que as propostas de Carré "careceron basicamente de uso e influencia no galego literario do período gobernado de maneira emblemática polo padrón que marcaba Ramón Piñeiro e o seu grupo" (Alonso Pintos 2006: 23-24). Nas "Verbas limiares" do seu Diccionario galego-castelán explicita Carré (1933: 6) a súa vontade de consagrar os usos gráficos dominantes na tradición literaria contemporánea que xa utilizara no seu primeiro traballo gramatical. Estes usos serán os que primen tamén na súa obra de posguerra e de modo particular no Epítome, onde tanto ratifica o uso da terminación -zón, que porén non facía parte da tradición literaria maioritaria, canto do grafema $<x>$ para o son fricativo prepalatal xordo en substitución dos etimolóxicos $\langle\mathrm{j}\rangle,\langle\mathrm{g}\rangle$. Isto é, Carré defendeu por razóns de uso histórico a terminación -zón e non as grafías etimolóxicas do son fricativo prepalatal, o que non deixa de constituír un caso de incoherencia.

A modo de síntese, pódese dicir que o modelo xeral de lingua proposto por Carré Alvarellos no seu Epítome de gramática galega, a pesar de manter unha esencial continuidade co utilizado por el nos seus traballos anteriores de teor filolóxico, tanto gramáticas como dicionarios, resulta máis coherente e uniformado. Se no plano gráfico mantén o uso de apóstrofos, trazos e acentos propios da época das Irmandades da Fala en contra do criterio utilizado por Galaxia nas súas publicacións, será no plano morfolóxico onde o Epítome se mostre máis innovador: por un lado, universaliza a terminación -zón que era rexeitada por aquela e polos académicos e, por outro, consolida os plurais de tipo corazóns, xornaes, ouriñoes, picheles e perniles, coas súas excepcións, a mostrar neste caso vacilacións en parte semellantes ás da gramática de Galaxia ou ás das futuras normas académicas.

\section{Conclusión}

Na década de 60 da anterior centuria a RAG, baixo a presidencia e o decidido impulso de Martínez-Risco, tentou elaborar unha gramática de carácter institucional que servise de guía e orientación para acabar cunha práctica caótica que viña caracterizando a escrita en galego desde o período oitocentista. Visto que as dificultades eran tan grandes como as urxencias, xa desde o inicio se foi estendendo entre os académicos a opinión de se conformaren coa realización dunha gramática elemental ou sintética, isto é, dun epítome de gramática galega en expresión frecuentemente utilizada por algúns deles. Desde que Martínez-Risco accedeu á presidencia activouse unha Comisión de gramática que posibelmente podería ter levado a cabo o proxecto, non sen dificultades, se non irrompese en escena a figura de Piñeiro, membro dirixente do grupo de Galaxia que na altura pasou a controlar a RAG, sen el propio ser membro numerario dela. Piñeiro impuxo a paralización do proceso de elaboración do epítome gramatical e propiciou a realización dunha gramática da Editorial Galaxia, para cuxo obxectivo escolleu a figura de Carvalho Calero. Apareceu así a Gramática elemental del gallego común en 1966, que se foi reeditando en anos sucesivos e que foi a gramática de referencia desa década e da seguinte, antes de 'Carballo' se converter en 'Carvalho'.

O profesor da USC contou desde o inicio con todo o apoio solidario do grupo de Galaxia a que tamén pertencía, mais ese non foi o caso doutro académico, Carré Alvarellos, que ao ano seguinte, 1967, publicou a segunda gramática da década desde a soidade institucional, pois Piñeiro non só non confiaba na súa condición de lingüista como mesmo manobrou para o marxinar en todo o proceso de codificación idiomática levado a cabo na década. Mais, curiosamente, o modelo estandarizador de Carré, que en 1965 propuxera á RAG a adopción das solucións -zón e ao e que sempre criticara as cesións ao modelo do español, acabará por se parecer máis ao modelo de Carvalho das etapas finais da súa vida que ao do que colaborou directamente na redacción das primeiras normas da entidade. Ese modelo de galego autónomo, non dependente do español, fica reflectido con maior precisión no Epítome de gramática galega que no ano 
1969 presentou á RAG como máis unha tentativa de incidir no proceso normativizador desta e de evitar a que el xulgaba como deriva castelanizadora. Porén, máis unha vez, as súas propostas non foron tidas en conta e ese derradeiro contributo gramatical de Carré durmiu un longo sono de case 50 anos nunha gabeta.

\section{Referencias bibliográficas}

Agustini, Carmen Lúcia Hernandes (2004): A estilistica no discurso da gramática. São Paulo: Pontes.

Alonso Girgado, Luís / Élida Abal Santorum / Alexandra Cillero Prieto (eds.) (2009): Cadernos Ramón Piñeiro (XII). Cartas de Ramón Piñeiro a José Luis Pensado. [Santiago de Compostela]: Xunta de Galicia.

Alonso Girgado, Luís / María Cuquejo Enríquez / Carmen Fariña Miranda (eds.) (2004): Cadernos Ramón Piñeiro (V). Cartas de Ramón Piñeiro a Ricardo Carballo Calero. Santiago de Compostela: Xunta de Galicia.

Alonso Pintos, Serafín (2002): Para unha historia do estándar galego. As propostas do período 19661980. Madrid: UNED.

Alonso Pintos, Serafín (2006): O proceso de codificación do galego moderno (1950-1980). A Coruña: Fundación Pedro Barrié de la Maza.

Auroux, Sylvain (1994): La révolution technologique de la grammatisation. Introduction à I' histoire des sciences du langage. Liège: Mardaga.

Bagno, Marcos (2001[2000]): Dramática da língua portuguesa. Tradição gramatical, mídia \& exclusão social. São Paulo: Edições Loyola.

Carballo Calero, Ricardo (1966): Gramática elemental del gallego común. Vigo: Galaxia.

Carballo Calero, Ricardo (1979 [1966]): Gramática elemental del gallego común. Vigo: Galaxia.

Carballo Calero, Ricardo (2006): Epistolario a Fernández del Riego. Transcrición e edición de Dolores Vilavedra e Montserrat Pena. Vigo: Galaxia.

Carré Alvarellos, Leandro (1928): Diccionario Galego-Castelán e Vocabulario Castelán-Galego, vol. 1. A Coruña: Lar.

Carré Alvarellos, Leandro (1931): Diccionario Galego-Castelán e Vocabulario Castelán-Galego, vol. 2. A Coruña: Lar.

Carré Alvarellos, Leandro (1933): Diccionario Galego-Castelán e Vocabulario Castelán-Galego. A Coruña: Imprenta e Papelería Zincke Hermanos.

Carré Alvarellos, Leandro (1967): Gramática gallega. A Coruña: Moret.
Chao Espina, Enrique (1958): Curso de lengua portuguesa. Viveiro: Artes Gráficas A. Santiago.

Fernán-Vello, Miguel Anxo / Francisco Pillado Mayor (1986): Conversas en Compostela con Carballo Calero. Barcelona: Sotelo Blanco.

Fernández del Riego, Francisco (2000): Un epistolario de Ramón Piñeiro. Vigo: Galaxia.

Franco Grande, Xosé Luís (2004): Os anos escuros. A resistencia cultural dunha xeración. Vigo: Galaxia.

Freixeiro Mato, Xosé Ramón (1994): Sebastián Martínez-Risco na cultura galega. Santiago de Compostela: Laiovento.

González González, Manuel (2006): “Ramón Piñeiro: o compromiso coa lingua", en Encontro Ramón Piñeiro. Actas do encontro realizado pola Dirección Xeral de Creación e Difusión Cultural en Santiago de Compostela, o día 19 de outubro de 2005. Santiago de Compostela: Xunta de Galicia, 13-27.

Lapa, Manuel Rodrigues (2001): Cartas a Francisco Fernández del Riego sobre a cultura galega. Vigo: Galaxia.

Lausberg, Heinrich (1990 [1966]): Manual de retórica literaria. Fundamentos de una ciencia de la literatura. Madrid: Gredos.

López Varela, Elisardo (2001): Unha casa para a lingua. A Real Academia Galega baixo a presidencia de Manuel Murguía (1905-1923). A Coruña: Espiral Maior.

Maceira Fernández, Xosé Manuel (2014): Leandro Carré. Un século de cultura e compromiso. Santiago de Compostela: Alvarellos.

Monteagudo, Henrique (2007): "Limiar", en Ramón Piñeiro, A linguaxe e as linguas. Vigo: Galaxia, 9-46.

Piñeiro, Ramón (2007 [1967]): A linguaxe e as linguas. Vigo: Galaxia.

Piñeiro, Ramón / Basilio Losada (2009): Do sentimento á conciencia de Galicia. Correspondencia (1961-1984). Edición de María Xesús Lama e Helena González. Vigo: Galaxia.

Real Academia Gallega (1971): Normas ortográficas e morfolóxicas do idioma galego. A Cruña: Imp. Moret. 
Risco, Sebastián (1968): "Función da Academia no futuro da Língoa", en O porvir da lingua galega. Lugo: Círculo de las Artes, 21-25.

Sánchez Rei, Xosé Manuel (2005): “Trazos xerais da tradición gramatical galega", Revista Galega de Filoloxía 6, 93-121.
Santamarina Fernández, Antón (2009): "Informe de Ramón Piñeiro á Real Academia Galega", Boletín da Real Academia Galega 370, 7-17.

Villanueva Gesteira, María Dolores (2015): A Editorial Galaxia: proxecto e traxectoria 1950-1963. Tese de doutoramento dispoñíbel en https://minerva. usc.es/xmlui/handle/10347/14740 